\title{
The Impact of Continuous Improvement Process in Achieving Tourism Organizational Excellence - An Exploratory Study at the High Commission for Hajj and Umrah in Iraq
}

\author{
Hussain Abbas Jaber, Assistant Professor Dunya Tariq Ahmed
}

DOI: $10.37648 /$ ijrssh.v10i04.011

Received:04 ${ }^{\text {th }}$ September, 2020; Accepted:01st October, 2020; Published:15th October, 2020

\begin{abstract}
The philosophy of continuous improvement is a relatively recent management method that aims to improve the improvement of the level of performance and service provided in service institutions, and the study aims to demonstrate the level of use of tools for continuous improvement in (the High Commission for Hajj and Iraqi Umrah), as well as to explain the impact of adopting the requirements of continuous improvement and good application In order to achieve tourism organizational excellence. The problem of the study is summarized in the weakness of the authority's possession of the requirements and capabilities necessary to implement the approach to continuous improvement, and the importance of the study lies in promoting the concept of continuous improvement and its importance to achieve guest satisfaction.

The questionnaire was used as a main tool to collect data that was distributed to a random sample of (155) individuals from (upper and middle departments) in the authority, and a set of statistical methods were used to find the level of importance of study variables and test the correlation relationship and influence of the independent variable (continuous improvement) In the dependent variable (organizational excellence) through the use of the statistical program (SPSS), the twenty-third edition and the statistical methods represented in (natural distribution test, percentages, arithmetic mean, standard deviation, difference coefficient, simple correlation coefficient "pearson", simple regression coefficient, Multiple regression coefficient), and after (planning) was the most influential in organizational excellence

The most prominent conclusions were: Support and commitment of senior management in applying the approach to continuous improvement and its inclusion in the strategic plan of the Authority. The study reached a set of recommendations, perhaps the most prominent of them: the need to take advantage of the feedback in order to take corrective measures for all deviations from the plans in place
\end{abstract}

\section{INTRODUCTION:}

The process of continuous improvement represents an essential strategic tool for the growth and success of organizations operating under a highly competitive environment characterized by speed and associated with globalization and technological development. To face all these challenges, it has become imperative for organizations to understand the rules of competition and reconsider the mechanism of their dealing with their environment and rely on basic pillars represented in human and financial resources and technology, and by 
using the technology of continuous improvement in their processes, activities and services to enable them to compete and provide these services with high quality and lowest costs to obtain guest satisfaction Thus achieving organizational excellence.

\section{First:The research problem:}

The research problem emerges with the need to emphasize keeping pace with developments in the field of quality and the process of continuous improvement, as adopting methods of continuous improvement process works to reduce costs and waste that affect efficiency and thus provide high-quality services that enhance the organization's ability to achieve its main objectives Down to the tourism organizational excellence. Hence, several questions can be raised, as follows:

1. Is there an understanding and awareness of a process for continuous improvement among the employees of the Supreme Commission for Hajj and Umrah in Iraq?

2. What is the level and importance of the continuous improvement process in the High Commission for Hajj and Umrah in Iraq?

3. Does the Supreme Commission for Hajj and Umrah in Iraq have the requirements and capabilities needed to implement the approach to the continuous improvement process?

4. Does the Supreme Commission for Hajj and Umrah in Iraq adopt a process of continuous improvement? Which of its dimensions receives the most attention to it?

\section{Second: The importance of research: -}

The importance of research is highlighted by the following: -

1. Contributing to spreading the application of concepts and principles (the process of continuous improvement) and increasing the awareness and awareness of the upper and middle administrations of the importance of this system in achieving the tourism organizational superiority of the Supreme Commission for Hajj and Umrah in Iraq in light of the rapid environmental changes.

2. The possibility of diagnosing the reality of the process of continuous improvement for the purpose of knowing the appropriate foundations to achieve the goals of the guests and to achieve added value for the Supreme Commission for Hajj and Umrah in Iraq.

3. Determine the availability of the requirements possessed by the Supreme Commission for Hajj and Umrah in Iraq to apply the approach to the process of continuous improvement, which will positively reflect on achieving the organizational excellence of tourism.

\section{Third: Research objectives:}

The research aims at the following:

1. Knowing the extent of the workers 'understanding and awareness of the process of continuous improvement in the Supreme Commission for Hajj and Umrah in Iraq.

2. Indication of the level of continuous improvement processes in the Supreme Commission for Hajj and Umrah in Iraq.

3. Raising the interest of the administration of the Supreme Commission for Hajj and Umrah in Iraq to adopt the approach of the continuous improvement process to achieve the tourism organizational excellence.

4. Determine the dimensions of the continuous improvement process that most affect the tourism organizational excellence and the service provided to the guests.

\section{Fourth: The hypothetical outline of the research:}

In light of the research problem and by relying on its variables and in order to achieve its objectives, a hypothetical scheme has been developed which depicts the relationship between the independent variables and the dependent variable. Figure (1) shows the hypothetical outline of the research as follows:

1. Continuous improvement process:It is the independent variable as it was addressed through its four dimensions that were chosen according to (Deming, 2018) which are (planning, implementation, auditing, correction).

2. Tourism Organizational Excellence:It is the dependent variable as it was addressed through its six dimensions that were tested according to (Malcolm Baldrej model), namely (operations, strategic planning, focus on guests, participation, information, analysis and knowledge, resources) (Malcolm, 2011) 


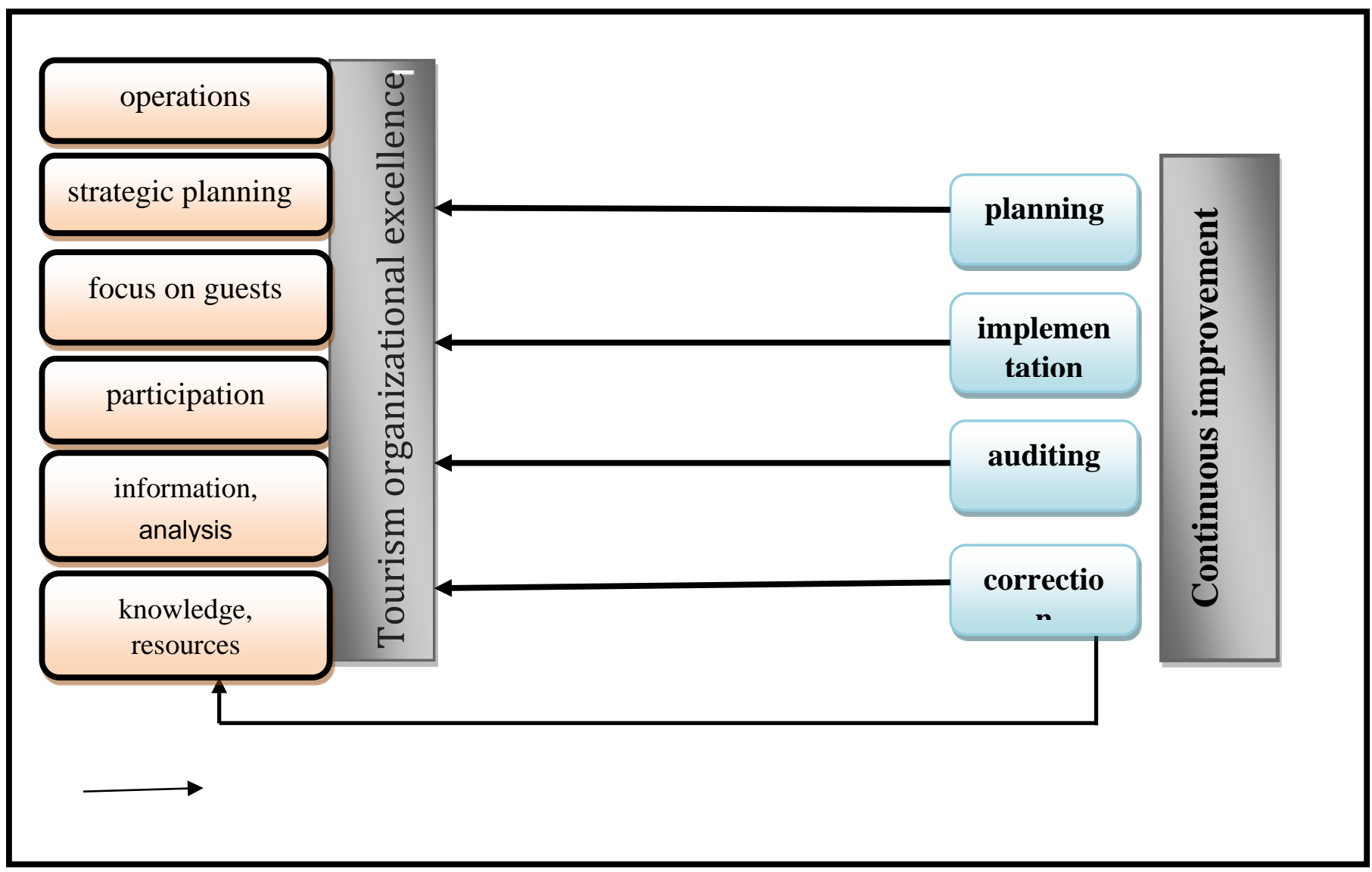

Figure (1) the hypothetical outline of the research

Source: From the researcher's numbers, depending on the literature related to the topic.

Fifth: Research hypotheses: - The second main hypothesis: There is a statistically significant impact of the process of continuous improvement in the tourism organizational excellence. The following sub hypotheses are divided into: -

The first sub-hypothesis: - There is a statistically significant impact of the planning process on the tourism organizational superiority.

The second sub-hypothesis: - There is a statistically significant impact of a process to implement in the tourism organizational excellence.

The third sub-hypothesis: - There is a statistically significant impact of the process of auditing the tourism organizational superiority.

The fourth sub-hypothesis: - There is a statistically significant effect of the correction process in the tourism organizational superiority.

Sixth: Research methodology:In his study, the researcher relied on a descriptive (analytical) approach to achieve goals and test hypotheses.

Seventh: Study Society and Sample:- The High Commission for Hajj and Umrah in Iraq was chosen as a community for the study (field of application). The study sample was represented by the upper and middle administrations in (the Supreme 
Commission for Hajj and Umrah in Iraq), whose number is (180) individuals to accurately represent the study population. The questionnaire was distributed to them.

\section{THE FIRST TOPIC: THE THEORETICAL ASPECT OF THE RESEARCH:}

\section{First: the process of continuous improvement}

1- The concept of the continuous improvement process: The concept of the continuous improvement process is "an administrative philosophy that seeks to work on continuously developing processes and activities related to machines, materials, people and production methods" (Ahmad, 2008: 181). The process of continuous improvement is the improvement and change for the better and the continuous improvement process focuses on all functions and processes within the organization (Bwemelo, Gordian S, 2017: 1). Because of the multiplicity and divergence of the trends and purposes of the continuous improvement process, many literature and studies did not agree on a specific concept for the continuous improvement process. Many writers and researchers have gone on to explain the concept of continuous improvement, each according to his point of view, as shown in Table (1):

\begin{tabular}{|l|l|l|}
\hline The concept & Year and Page & Researcher name \\
\hline $\begin{array}{l}\text { "The philosophy that total quality management needs in } \\
\text { order to improve every aspect of the process, the goals of } \\
\text { perfection that will never be achieved, but the organization } \\
\text { seeks to reach it". }\end{array}$ & Heizer et al \\
\hline $\begin{array}{l}\text { "The philosophy that seeks to make improvements that } \\
\text { never end during the process of converting inputs into } \\
\text { outputs". }\end{array}$ & Stevenson \\
\hline $\begin{array}{l}\text { "The process that includes continuous, iterative and } \\
\text { incremental improvements that the organization undertakes } \\
\text { to fulfill the client's desires and expectations and to enhance } \\
\text { its ability to survive for the sake of leadership". }\end{array}$ & $\mathbf{2}$ & $\mathbf{3}$ \\
\hline $\begin{array}{l}\text { "It is a philosophy that improves all contract steps that are } \\
\text { related to the process of converting inputs into outputs in a } \\
\text { permanent and continuous manner". }\end{array}$ & $2019: 23$ & $\mathbf{4}$ \\
\hline
\end{tabular}

Table (1) The concept of the process of continuous improvement from the viewpoint of some writers and researchers

Source: From the researcher's numbers, depending on the literature related to the topic.

Based on the foregoing, we find that the process of continuous improvement is a set of processes and procedures that represent the philosophy of the tourism organization to raise the level of quality of the services it provides, in order to achieve the wishes and expectations of the guests, reduce costs, and make improvements to those services continuously and not stop at a certain limit, and develop practical methods Continuous improvement, and possession of the ability to convert inputs into outputs, which enhances the capabilities of the tourism organization and achieves its competitive advantage.

2- The importance of the continuous improvement process: - The importance of the continuous improvement process is summarized as follows: -

1. The process of continuous improvement is not a technique, tool, or method, but rather a way of life that 
focuses on the guest and not on the market share, so it is one of the basic pillars for the success of organizations and their continuation in the market.

2. The process of continuous improvement is a race without an end line. It is an endless stage because there are areas for improvement throughout the organization.

3. Continuous improvement focuses on the What and How methodology, not on the Who.

4. That the process of continuous improvement is based on the idea of prevention is better than cure through a principle that I have been working right from the start (AlJubouri, 2008: 266).

3- Objectives of the Continuous Improvement Process: The philosophy of the continuous improvement process aims to achieve two main objectives: -

1. General objective: To make all efforts to make the process of continuous improvement appear easy in all parts of the organization and is related to all organizational activities and capabilities when the guest delivers the good or service.

2. Special objective: to emphasize the processes that make the completed work complete (Al-Abadi et al., 2008: 56) and (Al-Taie et al., 2009: 199).

4- Dimensions of the continuous improvement process: The continuous improvement process has a set of dimensions as follows: -

1. Planning: We mean by it the study of the process and the collection of data to identify obstacles, then analyze that data, develop a plan for the improvement process, define the basic goals and set a set of criteria to measure success. This stage includes five stages, which are as follows:

Collecting information about the process to be improved at the current time.

Discussing information and identifying obstacles and errors.

Analyzing and explaining the causes of obstacles and errors.

Developing the appropriate plan to avoid obstacles and errors and to conduct the improvement process.
- Defining the criteria for evaluating the improvement process after the implementation process (Aqili, 2009: 139).

2. Implementation: Executing what was planned and with a very narrow scope for the purpose of experimenting and collecting the necessary data on performance.

3. Auditing: The results obtained through the implemented process are evaluated and compared to the goals and specifications set to determine whether the objectives were achieved or not.

4. Correction: Through the evaluation results, we can make adjustments to the plans and processes. If the plan is successful, then a new improvement process will start at a new level and the cycle continues (life cycle). (Krajwiski et al, 2013: 121) (Stevenson, 2018: 394), (Heizer \& et. Al, 2017: 220) and (Hady and others, 2011: 10).

\section{SECOND: TOURISM ORGANIZATIONAL EXCELLENCE}

\section{1- The concept and importance of tourism organizational superiority}

A- The concept of organizational tourism excellence: Excellence is a term that came from the Latin language, which means (superior quality), meaning that it is intended to reach the highest levels through a specific work that achieves excellence and exceeds expectations to create new opportunities as a result of using knowledge (Santos \& Others, 2012: 274). ). The term excellence means a group of processes aimed at building capabilities and achieving efficiency at work (Salem, 2018: 41).

We find that the term Excellence increased in use significantly within the style of management thought in the seventies and eighties of the last century, such as rethinking the objectives of the guests and productivity for the survival and growth of the tourism organization, so it must adopt excellence (Garcia, 2016: 2). The administrative definitions of organizational excellence differed according to the different viewpoints of researchers and writers, as the researcher touched on a number of concepts, they cited pertaining to organizational excellence, as shown in Table (2). 


\begin{tabular}{|c|c|c|c|}
\hline The concept & Year and Page & Researcher name & No \\
\hline $\begin{array}{l}\text { It is the stage of reaching the optimal level of } \\
\text { overall performance through two basic } \\
\text { elements: the organization's commitment to } \\
\text { high standards that develop its various } \\
\text { resources, operations and activities, as well as } \\
\text { the overall roles and diverse practices at all } \\
\text { levels of management that work to achieve } \\
\text { success, growth and organizational } \\
\text { sustainability. }\end{array}$ & $2017: 75$ & Alshadidy & 1 \\
\hline $\begin{array}{l}\text { It is considered a positive indicator of } \\
\text { employees' performance and creative abilities, } \\
\text { and it is the highest level of performance that } \\
\text { employees can achieve by balancing the } \\
\text { desires of customers and expectations of } \\
\text { stakeholders in order to achieve long-term } \\
\text { organizational success in order to achieve } \\
\text { organizational excellence. }\end{array}$ & $2018: 43$ & Salim & 2 \\
\hline $\begin{array}{l}\text { It is the organization's excellence in } \\
\text { performance that exceeds the expected } \\
\text { performance by harnessing all material and } \\
\text { human resources, establishing good relations } \\
\text { with all its clients, identifying the } \\
\text { performance of its competitors, and } \\
\text { diagnosing its strengths and weaknesses. }\end{array}$ & 2019:307 & Abd allah and omer & 3 \\
\hline
\end{tabular}




\begin{tabular}{|l|l|l|}
\hline $\begin{array}{l}\text { It is achieving the goals and obtaining the } \\
\text { highest levels of success, and since excellence } \\
\text { is preceded by effective planning, it has } \\
\text { become in itself a great challenge due to the } \\
\text { intensity of competition between } \\
\text { organizations. }\end{array}$ & & fadel \\
\end{tabular}

Table (2) The concept of organizational excellence according to the viewpoint of some researchers and writers

Source: From the researcher's numbers based on the literature related to the topic.

Based on the foregoing, we explain that the tourism organizational excellence is a pattern of high functional performance represented by the intellectual and cognitive capabilities and skills of the workers of the tourism organization, which can achieve a balance between the needs and desires expected for both the guest and the organization, in order to reach the tourism organizational excellence And to gain a new position in the market and achieve a competitive advantage.

B- The importance of tourism organizational excellence: - The importance of organizational excellence in the development of human resources is evident through the establishment of the skills of workers and the relationships between them, and learning to facilitate the work of work teams and enhance their strategic role, as organizational excellence contributes by directing it to focus on procedural processes, and to being a resource that has a strategic impact. Critical to efficiently achieving the organization's goals (Abdel-Wahab, 2016: 90).

2- Tourism Organizational Excellence Objectives: Organizational excellence seeks to achieve the goals of interest in innovation, creativity, creating added value at the organization level, continuous improvement of the administrative process, developing human resources and encouraging them to participate, directing management practices towards the future, and focusing on the efforts of employees from In order to achieve customer satisfaction (Abdel Wahab, 2016: 92). The goal of organizational excellence is to create a qualified workforce that has the ability to produce products that exceed the expectations of the customer, create intrinsic value that fulfills his desires, and develop awareness towards achieving the goals of the organization by encouraging innovation and creativity and encouraging effective communication (Blcker, 2016: 168).

3- Dimensions of organizational tourism excellence: Organizational excellence is based on a number of dimensions through which the organization's superiority is measured, and whether it has achieved its charisma within the required level or not, and through the study of organizational excellence, we notice the presence of variation and diversity in destinations Many writers and researchers looked at the dimensions of organizational excellence, and the researcher dealt with a number of dimensions in the theoretical and practical sides, and chose six dimensions that achieved the most agreement to be the current dimensions of the research.

1. Focus on Operations: - Operations are defined as "a set of interrelated and interacting activities between them and the procedures associated with transforming the organization's inputs into outputs (Mitonneau, 2006: 38). This dimension focuses on creating value for all stakeholders and focusing on evaluation., Continuous improvement, organizational learning, agility, flexibility and operational efficiency, accomplishing the process in less time, focusing on designing new goods and services that satisfy the needs and desires of guests, and monitoring performance levels in competing organizations that provide the same services (Badri, et, al, 2006: 1126).

2. Strategic Planning: - This standard is considered one of the effective and main criteria in setting the vision and mission of the organization, and it defines its objectives, 
and sets up mechanisms for implementing and developing strategic plans and finding alternatives to them, so that the organization can face the obstacles and difficulties it faces (Al-Dajani, 2011: 97 ). Besterfield (2009: 70) shows that strategic planning is a multi-faceted process that is characterized by comprehensiveness and includes (rational and objective thinking) in order to build a clear and comprehensive vision of all environmental variables that affect the organization's work and the practice of its activities.

3. Focus on the guests: - Organizations are interested in focusing on the requirements, needs and desires of the guests and the expected markets, as well as building good relations with them, and focus on the main factors that achieve the satisfaction of the guests and increase their numbers in the future, thus expanding the business of the organization. The flow of information between the guests and the organization gives the organization clear-cut ideas (Bose, 2012: 116). The interest of the guests is achieved through the participation of all employees in building the concept of loyalty to the guests by building good and strong relationships with them and contacting them continuously through direct and indirect methods of communication (Abu Mandil, 2008: 88).

4. Participation: - This criterion represents the organization's plans to manage its external partnerships and internal resources in order to support its strategies and policies and to operate its operations with high efficiency through the participation of stakeholders. Therefore, participation with its actual assets leads to finding quick and appropriate solutions to all the problems of the guest. (2008: 157). The involvement of workers in setting the organization's strategies, and in the process of organizational development, shows the reality of the high competence of working individuals and at all organizational levels in order to carry out the development process to the fullest (Al-Sharif, 2013: 32).

5. Information, analysis and business results: Information, analysis and business results: - This standard focuses on gathering and analyzing information and providing those who need it in a timely manner and updating it on an ongoing basis. It includes everything related to achieving tourism organizational excellence, especially information related to guests, market conditions and competitors. And suppliers (Al-Qazzaz and others, 2009: 223).

6. Focus on resources: - This criterion focuses on managing all the organization's resources (financial, human, data, guests, and others), and that this standard represents one of the complex and critical activities of the organization (Harrington, 2011: 1-5) . The superior organizations have the ability to manage their resources and develop them continuously, and spread them among workers at all individual and collective levels (work teams) in order to support strategies and policies, and empower employees, which is based on the team's sense that it is part of superiority and success. Therefore, the superior organizations intend.

Table (3) Analysis of the dimensions of the continuous improvement process in tourism organizational excellence

\begin{tabular}{|l|l|l|l|l|l|l|l|l|}
\hline indicati \\
on
\end{tabular}




\begin{tabular}{|c|c|c|c|c|c|c|}
\hline moral & 0.000 & 214.026 & 0.583 & 0.583 & 1.622 & Correction \\
\hline moral & 0.000 & 342.985 & 0.692 & 0.772 & 0.830 & $\begin{array}{l}\text { Continuous } \\
\text { improvement } \\
\text { process }\end{array}$ \\
\hline
\end{tabular}

Source: prepared by the researcher based on the outputs of SPSS V.23.

Through Table No. (3), an analysis of the results of testing the following hypotheses shows: -

Test the main hypothesis: - There is a statistically significant effect of the process of continuous improvement and the tourism organizational superiority). As the analysis will be according to the simple linear regression model as follows: -

$$
\begin{aligned}
& \mathrm{Y}=\alpha+\beta(\mathrm{X}) \\
& \mathrm{Y}=0.830+0.772(\mathrm{X})
\end{aligned}
$$

The value of $(F)$ computed between the process of continuous improvement and the tourism organizational excellence was $(342,985)$. It is greater than the tabular (F) value of (4.03) at a level of significance (0.05) and accordingly we accept the hypothesis which states that there is a statistically significant effect of the process of continuous improvement and the tourism organizational superiority (at a level of significance (5\%) i.e. with a degree of confidence (95\%) And this indicates the existence of a statistically significant impact of the process of continuous improvement and tourism organizational excellence. That is, continuous improvement has an effective and essential effect on the tourism organizational excellence, that is, the more the research sample seeks to apply the process of continuous improvement at the level of the organization as a whole, in a continuous and thoughtful manner, the more it helps to improve the organization's levels and gradually raise it to the levels of tourism organizational excellence.

Through the value of the coefficient of determination $\left({ }^{2} \mathrm{R}\right)$ of $(0.692)$, it becomes clear that the process of continuous improvement explains (69\%) of the variables that occur to the organizational excellence of tourism, while the remaining percentage (31\%) is due to other variables that are not included in the research model.

It is evident through the value of the marginal slope coefficient () of $(0.772)$ that increasing the continuous improvement process by one unit will lead to an increase in the tourism organizational advantage by $(77 \%)$.

The value of the constant $(\alpha)$ in the equation (0.830), meaning when the continuous improvement process is equal to zero, the tourism organizational superiority will not be less than this value.

1. The first sub-hypothesis test: - There is a statistically significant significant effect of planning on the tourism organizational excellence, as the analysis will be done according to the simple linear regression model, as follows:

$$
\begin{aligned}
& \mathrm{Y}=\alpha+\beta(\mathrm{X}) \\
& \mathrm{Y}=1.198+0.658(\mathrm{X})
\end{aligned}
$$

A- The value of $(F)$ computed between the planning process in the tourism organizational superiority reached $(191,815)$. It is greater than the tabular $(\mathrm{F})$ value of (4.03) at the level of significance (0.05) and accordingly we accept the hypothesis which states that there is a statistically significant effect of the planning process in the tourism organizational superiority at a level of significance (5\%), that is, with a degree of confidence (95\%). This indicates the existence of a statistically significant impact of the planning process in the tourism organizational excellence, that is, that the planning process properly and in accordance with developments and environmental variables will help improve performance and achieve tourism organizational excellence.

B- Through the value of the coefficient of determination $\left({ }^{2} \mathrm{R}\right)$ of $(0.556)$, it becomes clear that the planning process explains 55\% of the variables that occur to the organizational tourism superiority, while the remaining $45 \%$ is due to other variables not included in the research model. . 
C- It is clear from the value of the marginal slope coefficient () of (0.658) that increasing the planning process by one unit will lead to an increase in the tourism organizational advantage by $(65 \%)$.

D- The value of the constant $(\alpha)$ in equation (1.198), meaning when the planning process is equal to zero, the tourism organizational superiority will not be less than this value.

2. The second sub-hypothesis test: - There is a statistically significant effect of the implementation process on the tourism organizational superiority) as the analysis will be done according to the simple linear regression model, as follows: -

$\mathrm{Y}=1.346+0.642(\mathrm{X})$

A- The value of $(F)$ calculated between the implementation process in the tourism organizational superiority reached (166.269). It is greater than the tabular (F) value of (4.03) at the level of significance (0.05) and accordingly we accept the hypothesis which states (there is a significant effect of significant significance for the dimension of the implementation process in the tourism organizational superiority) at a level of significance $(5 \%)$ i.e. with a degree of confidence $95 \%$ ). This indicates that the implementation process has an effective and good effect on the tourism organizational excellence. That is, whenever there is a correct implementation and according to what is planned, the more it helps to achieve the tourism organizational excellence.

B- Through the value of the determination coefficient $\left({ }^{2} \mathrm{R}\right)$ of $(0.521)$, it becomes clear that the implementation process explains $(52 \%)$ of the variables that occur to the organizational tourism superiority, while the remaining $48 \%$ is due to other variables not included in the model search.

$\mathrm{T}$ - It is clear from the value of the marginal slope coefficient () of (0.642) that increasing the implementation process by one unit will lead to an increase in the tourism organizational advantage by (64\%).

D- The value of the constant $(\alpha)$ in equation (1.346), meaning when the implementation process is equal to zero, the tourism organizational superiority will not be less than this value.
3. The third sub-hypothesis test: - There is a statistically significant impact on the process of auditing the tourism organizational excellence, as the analysis will be done according to the simple linear regression model, as follows

$$
\mathrm{Y}=1.185+0.696(\mathrm{X})
$$

A- The value of $(F)$ computed between the audit of the tourism organizational superiority is $(275,752)$. It is greater than the tabular value (F) of (4.03) at the level of significance (0.05) and accordingly we accept the hypothesis which states that there is a statistically significant impact of the process of auditing the tourism organizational superiority at a level of significance $(5 \%)$ that is, with a degree of confidence (95\%). Which indicates that the audit has a fundamental effect on the tourism organizational excellence, that is, whenever there is an audit of administrative work, activities and procedures, the more it helps to achieve tourism organizational excellence.

B- Through the value of the coefficient of determination $\left({ }^{2} \mathrm{R}\right)$ of $(0.643)$, it becomes clear that the audit process explains (64\%) of the variables that occur to the organizational excellence of tourism, while the remaining percentage $(36 \%)$ is due to other variables not included in the model search .

C- It is clear through the value of the marginal propensity coefficient () of (0.696) that increasing the audit process by one unit will lead to an increase in the tourism organizational advantage by (69\%).

D- The value of the constant $(\alpha)$ in equation (1.185), meaning when the audit process is equal to zero, the tourism organizational superiority will not be less than this value.

4. The fourth sub-hypothesis test: - There is a significant, statistically significant effect of the correction process on the tourism organizational superiority, as the analysis will be done according to the simple linear regression model, as follows:

$$
\mathrm{Y}=1.622+0.583(\mathrm{X})
$$

A- The value of (F) computed between the correction process in the tourism organizational superiority reached (214.026). It is greater than the tabular (F) value of (4.03) at the level of significance (0.05) and 
accordingly we accept the hypothesis which states that there is a statistically significant significant effect of the correction process in the tourism organizational superiority at a level of significance $(5 \%)$ i.e. with a degree of confidence (95\%) ). This indicates that there is an effect of the correction process in the tourism organizational superiority, meaning that correcting work procedures after auditing them and evaluating the works will help to reach the levels of tourism organizational excellence.

B- Through the value of the coefficient of determination $\left({ }^{2} \mathrm{R}\right)$ of $(0.583)$, it becomes clear that the correction process explains what percentage (58\%) of the variables that occur to the organizational excellence of tourism, while the remaining percentage $(42 \%)$ is due to other variables not included in Search form.
C- It is clear from the value of the marginal slope coefficient () of (0.583) that increasing the correction process by one unit will lead to an increase in the tourism organizational advantage by (58\%).

W- The value of the constant $(\alpha)$ in equation (1.622), meaning when the correction process is equal to zero, the tourism organizational superiority will not be less than this value.

Table (4) shows the statistical indicators among the dimensions of the process of continuous improvement in tourism organizational excellence, and it can be expressed in the following equation:

$$
\mathbf{Y}=\alpha+\boldsymbol{\beta}_{1} \mathbf{X}_{1}+\boldsymbol{\beta}_{2} \mathbf{X}_{2}+\boldsymbol{\beta}_{3} \mathbf{X}_{3}+\boldsymbol{\beta}_{4} \mathbf{X}_{4}
$$

$Y=0.860+0.155 X_{1}+0.152 X_{2}+0.372 X_{3}+0.228 X_{4}$

\begin{tabular}{|l|l|l|l|l|l|l|l|l|l|}
\hline \multicolumn{2}{|l}{$\begin{array}{l}\text { Table (4) shows the statistical indicators between the dimensions of the process of continuous improvement in the tourism } \\
\text { organizational excellence by using multiple linear regression }\end{array}$} \\
\begin{tabular}{|l|l|l|l|l|l} 
Value of \\
apperan \\
celevel $)$ \\
$(0.05$
\end{tabular}
\end{tabular}

Source: prepared by the researcher based on the outputs of SPSS V.23

A- The calculated value of $(\mathrm{F})$ for the estimated model is (86.580). It is greater than the tabular $(\mathrm{F})$ value of (2.56) at the level of significance (0.05). Accordingly, we reject the null hypothesis and accept the alternative hypothesis. This means that there is a statistically significant effect of the process of continuous improvement in the process of continuous improvement in the tourism organizational superiority at the level of significance (5\%), i.e. a degree Confidence (95\%). This indicates that the dimensions of the continuous improvement process have an effective and essential effect on the tourism organizational excellence. 
B- Through the value of the coefficient of determination $\left({ }^{2} \mathrm{R}\right)$ of $(0.698)$, it becomes clear that the dimensions of the continuous improvement process are able to explain (69\%) of the changes that occur to (tourism organizational excellence), while the remaining percentage $(31 \%)$ is related to other variables. Not included in the search form.

C- Using the (Stepwise) method for testing the variables and after removing the non-significant variables, it becomes clear that the model in the final form depends on the dimensions (planning, checking, correcting), as the value of (F) computed for the new model is (112.334), which is greater than the value of F)) The tabular data, amounting to (3.18) at a level of significance (0.05), i.e. with a degree of confidence $(95 \%)$. The model can be expressed in the final form as follows:

$$
\begin{aligned}
& =\mathrm{Y} \alpha+\beta 1 \mathrm{X} 1+\beta 3 \mathrm{X} 3+\beta 4 \mathrm{X} 4 \\
& =\mathrm{Y} 0.930+0.230 \mathrm{X} 1+0.431 \mathrm{X} 3+0.227 \mathrm{X} 4
\end{aligned}
$$

D- Through the value of the coefficient of determination $\left({ }^{2} \mathrm{R}\right)$ of $(0.691)$, it becomes clear that the dimensions (planning, auditing, correcting) are able to explain $(69 \%)$ of the changes that occur to (tourism organizational excellence) and the remaining percentage (31\%) It is dependent on other variables that are not included in the research model.

C- It is evident from the value of the marginal propensity coefficient of the planning process dimension of $(0.230)$ that an increase in the planning process by one unit will lead to an increase in (tourism organizational excellence) by (23\%).

$\mathrm{H}$ - It is evident from the value of the marginal propensity coefficient for the audit process dimension of $(0.431)$ that an increase in the audit process by one unit will lead to an increase in (tourism organizational excellence) by (43\%).

G- It is evident through the value of the marginal slope coefficient of the correction process dimension of $(0.227)$ that an increase in the correction process by one unit will lead to an increase in (the tourism organizational superiority) by $(22 \%)$.

Source: Prepared by the researcher based on the output of the AmosV.23 program

\section{CONCLUSIONS}

1. The results of the research showed that the Supreme Commission for Hajj and Umrah in Iraq pays clear attention to the process of continuous improvement, and this would ensure its survival and continuity in the market by providing various services with high-quality specifications that meet the wishes of the guests.

2. The results of the research showed that most of the correlation and influence relationships are significant between the dimensions of the continuous improvement process in the tourism organizational excellence. This indicates that the Supreme Commission for Hajj and Umrah in Iraq uses the dimensions of the continuous improvement process, but not at the required level, which calls for attention to all future dimensions of the continuous improvement process for its clear impact. In achieving tourism organizational excellence.

3. The results of the research showed that the Supreme Commission for Hajj and Umrah in Iraq relies on the process of continuous improvement in its four dimensions (planning, implementation, auditing, correction) and with varying proportions, after (planning) the highest level of response was recorded from the viewpoint of the sample, which indicates that the High Commission for Hajj And Umrah in Iraq is directed towards strengthening its ability to possess the capabilities and resources that enable it to formulate plans and policies, while after (correction) the lowest level of response was recorded from the viewpoint of the sample, and this indicates the weak interest of the Supreme Commission for Hajj and Umrah in Iraq to follow up and correct the results achieved.

4. The higher management of the Supreme Commission for Hajj and Umrah directs Iraq to keep pace with the community movement and its changes by developing remedial plans in remedial steps that precede the work impediments, which is the main pillar for achieving the organizational excellence of tourism. 
5. The results of the research showed that the Supreme Commission for Hajj and Umrah in Iraq implements and documents continuous improvement processes in the vision, mission and strategic objectives, and this is evidence of the real commitment of the higher management to the implementation of these processes.

6. The results of the research showed that the Supreme Commission for Hajj and Umrah in Iraq is responsive to internal environment variables to determine the strengths and weaknesses of its administrative levels, but it suffers from a weak response to external environment variables and this is due to the problems evident in the environmental scanning process and its negative impact on the ability to provide the necessary information. right on time .

\section{RECOMMENDATIONS}

1. Enhancing the awareness and awareness of the Supreme Commission for Hajj and Umrah in Iraq of the importance of applying the process of continuous improvement in order to implement all operations and activities and achieve tourism organizational superiority by employing its capabilities in the direction of spreading the culture of the continuous improvement process.

2. The keenness to invest in the positive relationship achieved between the process of continuous improvement and the organizational excellence of tourism, and to benefit from it in improving the reality of the services provided to its clients.

3. Enhancing the ability of the Supreme Commission for Hajj and Umrah in Iraq to predict future problems according to the analysis of the environment (internal, external, with the aim of providing the necessary information in a timely manner and showing the extent of the success of the plans in achieving the objectives of the Supreme Commission for Hajj and Umrah in Iraq and the guest together. "

4. The need to take advantage of the feedback system in order to take corrective measures for all deviations from the established plan.

5. Investing the results achieved from the dimensions of the continuous improvement process in a scientific and thoughtful manner, to become a basic base from which the Supreme Commission for Hajj and Umrah in Iraq to achieve the organizational excellence of tourism.

6. Adopting a financial system for a continuous improvement process that is transparent and accountable, and translating the concept of a continuous improvement process into practical performance, which greatly affects the achievement of tourism organizational excellence.

\section{REFERENCES}

\section{First: Arabic References: -}

1. Ahmed, Mahfouz Ahmad, "The Quality of Total Quality Management, Concepts and Applications", Wael Publishing House, Third Edition, Amman, Jordan, 2008.

2. Al-Abadi, Hashem Fawzi, Al-Taie Youssef Hajim, and Al-Asadi Afnan Abd Ali, 2008, "University Education Administration is a Modern Concept in Contemporary Administrative Thought", Al-Warraq Foundation for Publishing and Distribution, Amman, Jordan.

3. Hadi, Maytham Rabie, Nehme, Nagham Hussein, Hussein, Nujoud Shaker, 2011, "Improving Operations in Business Organizations" - An analytical study of process improvement tools used in some international companies, a research published in the Iraqi Journal of Management Sciences, College of Administration and Economics University of Karbala, Volume 7, No. 28.

4. Salem, Mona Issa, "The Role of Organizational Justice in the Excellence of Organizations": An exploratory study at the Institute of Technology - Baghdad, a master's thesis submitted to the Board of the College of Administration and Economics - Al-Mustansiriya University, which is part of the requirements for obtaining a higher diploma in office management, 2018. 
5. Al-Shididi, Osama Alaa Hamdallah, "The Impact of the Strategic Roles of the Human Resources Director in Achieving Organizational Excellence": A field study in a number of oil sector companies in Baghdad, a master's thesis submitted to the Board of the College of Administration and Economics - University of Baghdad, 2017.

6. Abdullah, Haydar Taha, Umair, Arak Abboud, "The Role of Strategic Agility in Achieving Organizational Excellence": A Field Study of a Sample of Private Colleges, Published Research, Al-Dinanir Magazine, Issue 15, 2019.

7. Najm, Shaima Fadel, 2019, The Role of Continuous Improvement Processes in Implementing Baghdad Municipality Contracts - Case Study in Projects Department in Baghdad Municipality, (Higher Diploma equivalent to Master in Municipal Administration), College of Administration and Economics, University of Baghdad.

8. Abdul-Wahab, Nadia, Lotfi, Suleiman, Sanaa, Mahmoud, "The Use of the European Excellence Model EFQM in Evaluating the Performance of Organizations Applied Research in Al-Nu'man General Hospital", University of Baghdad, College of Administration and Economics, 2016, Dinanir Magazine, Issue Eight.

9. Belker, Khalida Muhammad, 2016, "Achieving Organizational Excellence through the Educated Organization", New Economy Journal, Issue 14, Volume 1.

10. Al-Dajani, A. Ayad Ali,

\section{2-English References:}

11. Bwemelo, Gordian S. (2017), Acceptability and Feasibility of Kaizen As a Strategy for Improving SsmesPerformace in Tanzania, Business Education Journal, Volum I Issue III.

12. Stevenson, William J. ,(2018), " Operations Management", $13^{\text {th }}$ ed , Irwin McGraw - Hill , New York .

13. Heizer, Jay \& Render, Barry \&MUNSON ,Chuck , (2017)," Operations Management" $12^{\text {th }}$ ed : Prentice Hell New Jersey, USA.

14. Krajwiski et al,(2013)Operation management, processes and supply chains Global education10th ed, personal education limited ,England.

15. Santos, Seille Cristine Garcia,\& Almeida, Leandro da Silva,\&Werlang, Blanca Susana Guevara, (2012), Human Excellence: The Contribution of Personality, Vol. 22, No. 52,PP. 271-279.

16. Garcia. A, 2016, Towards Excellence Organization Founded in Human Identity, open access journal, V 4, Issue 1, p1-3.

17. NIST national institute of standards and technology, (2011), "Malcolm Baldrige National Quality Award", department of commerce, U. S. A. , E-mail: baldrige@nist.gov, Web: http:// www .nist.gov/baldrige or www.nist.gov/ baldrige/publications / progress _ leaders.cfm.

18. Mitonneau, Henri.,(2006),"Succeeding the process audit", 2nded, AFNOR, GUERRA

19. Badri ,Masood Abdulla ; Selim ,Hassan; Alshare ,Khaled ; Grandon „Elizabeth E.; Younis Hassan; Abdulla Mohammed;(2006); The Baldrige Education Criteria for Performance Excellence Framework; International Journal of Quality \&Reliability Management Vol. 23 No. 9,pp1118-115..

20. Besterfield, Dale, (2009), "Quality Control", 8th edition, Prentice Hall, U .S

21. Bose ,TarunKanti;(2012); Market Segmentation and Customer Focus Strategies and Their Contribution towards Effective Value Chain Management; International Journal of Marketing Studies Vol. 4, No. 3,pp113-121.

22. Harrington ,H.James , Creating organizational excellence, "Success Relies on Keen Project Management Processes" Parts 1,2,3,4,5, 2011 , plog .Harrington's - institute .com ,2011-2012. 